\section{Thirty years: mourning, celebration and what remains to be done}

\author{
Ruth E Malone
}

With this issue, Tobacco Control commemorates 30 years of publication and marks an anniversary that is cause for both mourning and celebration. Mourning, because over the last 30 years, millions of people have been killed by tobacco products, and millions more have been horribly disabled. Millions of families have lost their beloved elders prematurely and unnecessarily, wiping out the wisdom they could make available to younger generations as well as reducing their families' economic security. Millions of children and other family members have been harmed by their early exposure to secondhand smoke. Trillions of cigarette butts and other waste from tobacco products, toxic pesticides used in tobacco growing, and deforestation from tobacco growing and curing processes harm our environment. More than perhaps any other save the fossil fuels industry, the tobacco industry draws its sustenance from activities that hurt individuals, families, societies and the planet. It is a parasite, always seeking new blood, moving into countries where the pandemic has not yet taken hold. As papers in this special issue show, it remains the single biggest obstacle to ending the tobacco pandemic that began in the 20th century.

But this moment also calls for celebration, because the work accomplished in the tobacco control arena over the last 30 years has saved millions of lives, served as an example for other health movements, made the tobacco industry the poster child for truly evil corporate practices and begun to change the social meaning of the cigarette, the single most lethal and defective artefact in the history of civilisation. ${ }^{1}$ Today, tobacco use is falling fast in countries and jurisdictions that have enacted aggressive tobacco control policies, thereby creating healthier societies. Thousands around the globe are connected in their efforts to fight this pandemic - and this industry-through policies, public health interventions and litigation.

Social and Behavioral Sciences, University of California, San Francisco, CA, USA

Correspondence to Professor Ruth E Malone, Social and Behavioral Sciences, University of California, San Francisco, CA 94118, USA; ruth.malone@ucsf.edu
This journal has played an important role in highlighting the tobacco pandemic as a problem that is not merely the sum of individual behaviour choices or 'habits', as the tobacco industry liked to call tobacco addiction, much to the annoyance of the journal's first editor-in-chief, ${ }^{2}$ but is structurally, politically, and socially created and perpetuated by the actions (and inaction) of the industry, governments, and civil society. For the record, I touch here on just a few of the journal's contributions.

From its first year, the journal foregrounded the role of the tobacco industry in a section called Industry Watch that remains one of the journal's most popular features. For example, a report from Dr Alan Blum described the tobacco control advocacy efforts at the spring 1992 Philip Morris tobacco company shareholder meeting, ${ }^{3}$ including an appearance by former Marlboro model Wayne McLaren, who would be dead from cigarette-caused lung cancer at age 52 years just a few months later. ${ }^{4}$ Speaking out so directly about the industry was at the time a fairly daring thing for a scientific journal, presaging by decades the contemporary development of the active multidisciplinary research arena now focused on corporate disease vectors and commercial determinants of health.

Across the ensuing 30 years, Tobacco Control's primary contributions were not studies of the health effects of tobacco products or the reasons people used them, although such studies did occasionally appear in its pages. In fact, it is now formal journal policy that we rarely publish prevalence studies and studies of knowledge, attitudes and behaviour unless these are related to never-before-studied phenomena that could be important to policy initiatives. The focus was always tobacco control, intrinsically normative and explicitly recognising that tobacco was a problem requiring policy intervention. It was not merely a journal featuring research about tobacco in general, a distinction that some authors even today do not quite grasp-hence the occasional submission of a paper on how to increase tobacco trade between countries or testing some improved method of tobacco cultivation. These papers are summarily rejected as outside the scope of the journal.
Tobacco Control was also a leader in establishing policies against publishing work funded by tobacco companies or tobacco industry-funded groups, or by tobacco industry-supported authors, a topic of discussion in the journal long before our formal policy was developed. For example, in 1994, Dr Michele Bloch editorialised about the industry's role in funding research to use in court cases, intended to perpetuate the notion that the case was not yet closed on cigarettes causing disease. ${ }^{5}$ No one knew then just how deep the deception ran. In the ensuring years, as internal tobacco company documents were released to the public in multiple court cases, incontrovertible evidence of the industry's real aims in funding research was uncovered, including the 'special projects' screened primarily by lawyers to produce findings useful to the industry for litigation. ${ }^{6}$ Nevertheless, it was not until 2013 that the Tobacco Control senior editorial team established our policy, which was followed by other BMJ journals. ${ }^{7}$ In 2017, we reaffirmed the policy and addressed the issue of tobacco companies funding new nonprofit organisations to carry forward the industry's specific version of a 'harm reduction' agenda. ${ }^{8}$ Currently, we are involved in discussions with other journal editors about policies to address the range of new companies and entities acquired or funded by major tobacco companies, including pharmaceutical and device companies.

The journal has continued its longstanding commitment to try to integrate social justice considerations into our decision-making ${ }^{9}$ by working to encourage more work from low-resourced countries where both funding and academic publishing mentorship may be lacking. In 2012, the journal received fewer than 500 submissions. By 2021, over 750 submissions from over 60 countries were received. Stemming from a short-term grant-funded initiative secured in 2009 by now-Editor Emeritus Simon Chapman that aimed to increase the contributions from low/middle-income country authors, the journal's reviewers and senior editors have continued working with a small panel of dedicated volunteers. These individuals have taken under their wings many authors whose work had the bones of a good contribution but needed a bit more help-with writing and copyediting, paper structure or scientific analysis-to get across the peer review line to acceptance. We still need to do more, but the engagement of both researchers and advocates from around the world reflects the 
growing strength and global connectedness of the tobacco control movement and the journal's wide influence.

I want to make special mention of the journal's News Analysis and News and Views blog, another way the journal contributes to extending the broader conversations in the field. The News Analysis was also part of the journal from the start, featuring witty commentary on tobacco-related news. The blog, which began in 2010, has become a popular way to convey news, opinion and new information to the field quickly. These are never paywalled and always publicised on the journal's social media channels.

The journal's publishing metrics have increased almost continually across the years, to a record-high Impact Factor of 7.552 for 2020. Other metrics likewise place the journal in the top tier of its journal category. This is a tribute to all the authors, editors, and reviewers who contribute to shaping and disseminating the journal's content.

Much has been accomplished in tobacco control across the last three decades, led by advocates working on the ground and informed by the research and analysis published in Tobacco Control, each pushing the other forward. But much remains to be done if we are to ensure that the tobacco pandemic does not continue for another 30 years. As editors entrusted with the stewardship of the top journal in tobacco control policy, our priority is to continually scan the horizon, trying to understand the current moment, message and momentum, while watching for the research and analysis that may contribute most meaningfully.
Sometimes those contributions are as small as a letter reporting an evaluation or a public opinion survey. Sometimes they are blog or opinion pieces that offer new framings for old problems, or archival research that uncovers new truths about the tobacco industry that are still relevant today. Sometimes they are large surveys, economic analyses or epidemiological studies that expand our grasp of the scope of the tobacco problem. And sometimes they are reviews that open up new ways to think about what - taken together-a mass of individual studies mean. As editors, we do not always know what is going to turn out to be important, game-changing work.

The scientific and scholarly enterprise in any field can never entirely capture the ineffable aha, nor the taken-for-granted assumptions that are next to be challenged by new knowledge emerging from the churning rapids of research. But a journal constructs a shared conversation that creates the possibility of glimpsing these things, even for just a moment. We hope Tobacco Control's 30th anniversary issue, organised around the idea of change, opens new possibilities in your own thinking about how we can move forward together to finally bring the industrially produced tobacco pandemic to an end.

\section{Twitter Ruth E Malone @MaloneRuth}

Funding The authors have not declared a specific grant for this research from any funding agency in the public, commercial or not-for-profit sectors.

Competing interests https://tobaccocontrol.bmj. com/pages/wp-content/uploads/sites/49/2021/08/RuthMalone-DOI-2021.pdf

Patient consent for publication Not required.
Ethics approval This study does not involve human participants.

Provenance and peer review Not commissioned; not peer reviewed.

(c) Author(s) (or their employer(s)) 2022. No commercial re-use. See rights and permissions. Published by BMJ.

$$
\text { (A) Check for updates }
$$

To cite Malone RE. Tob Control 2022;31:121-122.

Tob Control 2022;31:121-122.

doi:10.1136/tobaccocontrol-2022-057281

\section{ORCID iD}

Ruth E Malone http://orcid.org/0000-0002-3324-2183

\section{REFERENCES}

1 Proctor RN. Golden holocaust: origins of the cigarette catastrophe and the case for abolition. Berkeley: University of California Press, 2011.

2 Davis RM. The language of nicotine addiction: purging the word 'habit' from our lexicon. Tob Control 1992;1:163-4.

3 Blum A. Cowboys, cancer, kids, and cash flow: the 1992 Philip Morris annual meeting. Tob Control 1992:1:134-7.

4 Gates $\mathrm{G}$. The sad last words of the Marlboro man. The Buffalo News, https://buffalonews.com/news/the-sadlast-words-of-the-marlboro-man/article_d09d24f70373-562c-86e5-720624e55912.htm/, 1992.

5 Bloch M. Tobacco industry funding of biomedical research. Tob Control 1994;3:297-8.

6 Glantz S, Slade J, Bero L, et al. The cigarette papers. Berkeley, CA: UC Press, 1996.

7 Malone RE. Changing tobacco control's policy on tobacco industry-funded research. Tob Control 2013;22:1-2.

8 The Tobacco Control Senior Editorial Team. Why Tobacco Control still won't publish tobacco industry funded work, even if the funding is laundered through PMI's new 'independent' foundation. Tobacco Control News and Views, 2017. Available: https://blogs.bmj.com/tcl 2017/10/23/why-tobacco-control-still-wont-publishtobacco-industry-funded-work-even-if-the-funding-islaundered-through-pmis-new-independent-foundation/

9 Malone RE. Peer reviewed journals, science and social justice. Tob Control 2012;21:1. 